\title{
BMJ Open Nurses' decision-making in ethically relevant clinical situations using the example of breathlessness: study protocol of a reflexive grounded theory integrating Goffman's framework analysis
}

\author{
Christine Dunger, ${ }^{1}$ Martin W Schnell, ${ }^{1}$ Claudia Bausewein ${ }^{2}$
}

To cite: Dunger $C$, Schnell MW, Bausewein C. Nurses' decision-making in ethically relevant clinical situations using the example of breathlessness: study protocol of a reflexive grounded theory integrating Goffman's framework analysis. BMJ Open 2017;7: e012975. doi:10.1136/ bmjopen-2016-012975

- Prepublication history and additional material is available. To view please visit the journal (http://dx.doi.org/ 10.1136/bmjopen-2016012975).

Received 7 June 2016 Revised 29 November 2016 Accepted 17 January 2017

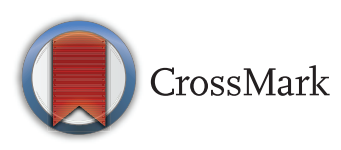

${ }^{1}$ Institute for Ethics and Communication in Healthcare, Witten/Herdecke University, Witten, Germany ${ }^{2}$ Department of Palliative Medicine, LudwigMaximilians-University Munich, Munich University Hospital, Munich, Germany

Correspondence to Christine Dunger; Christine.Dunger@uni-wh.de

\section{ABSTRACT}

Introduction: Decision-making (DM) in healthcare can be understood as an interactive process addressing decision makers' reasoning as well as their visible behaviour after the decision is made. Other key elements of DM are ethical aspects and the role as well as the treatment options of the examined professions. Nurses' DM to choose interventions in situations of severe breathlessness is such interactions. They are also ethically relevant regarding the vulnerability of affected patients and possible restrictions or treatment options. The study aims to explore which factors influence nurses' DM to use nursing interventions in situations where patients suffer from severe breathlessness.

Methods and analysis: Qualitative study including nurses in German hospital wards and hospices. A triangulation of different methods of data collectionparticipant observation and qualitative expert interviews —and analysis merge in a reflexive grounded theory approach which integrates Goffman's framework analysis. It allows an analysis of nurses' selfstatements about DM, their behaviour in relevant clinical situations and its influences. Data collection and analysis will be examined simultaneously.

Ethics and dissemination: Informed consent will be gained from all participants and the institutional stakeholders. Ongoing consent has to be ensured since observations will take place in healthcare institutions and many patients will be highly vulnerable. The study has been evaluated and approved by the Witten/ Herdecke University Ethics Committee, Witten, Germany. Results of the study will be published at congresses and in journal papers.

\section{INTRODUCTION}

Breathlessness occurs in cardiopulmonary and oncological diseases and is defined as the 'subjective experience of breathing

\section{Strengths and limitations of this study}

- This qualitative study will provide new insights on nurses' decision-making (DM) and its influencing factors based on methodology and data triangulation including participants' statements and care situations observed in clinical practice.

- The protocol describes a carefully developed and open but structured approach in researching DM including the theoretical concepts of Goffman's framework analysis which can be reproduced in other clinical contexts.

- Limitations may be connected to challenges in field access as some organisations under restrictive conditions may refuse even though these conditions may have an even more important role in DM.

- As this is a qualitative study, results are valid for the population and the circumstances under examination, however they shall not be generalised easily.

discomfort that consists of qualitatively distinct sensations that vary in intensity'. ${ }^{1}$ The experience and sensory qualities can be distinguished according to underlying mechanisms and "vary in their unpleasantness and in their emotional and behavioural significance'. ${ }^{2}$ Patients often feel a loss of control or even anxiety and panic. ${ }^{3-6}$ Therefore, they can be seen as highly vulnerable.

Professional nurses need to react to this clinical situation with adequate interventions according to patients' needs. Current research suggests that these interventions should include the clinical and the psychosocial situation of patients with breathlessness. ${ }^{7} 8$ Pharmacological interventions as well as non-pharmacological interventions (NPI) should be considered..$^{9}$ 
Nurses' treatment options and decision-making (DM) in severe breathlessness

As seen in studies on the implementation of interventions ${ }^{10-13}$ or in guidelines recommending interventions, ${ }^{14} 15$ nurses' treatment options in breathlessness vary in different countries and settings, as do the duties and legal responsibility they have. Other issues include a lack of institutional support for specialised nurses, too little time and few possibilities for systematic reflection or supervision. ${ }^{16} 17$ The interventions are mostly complex NPI used by nurses with special, often academic training. International Nursing Guidelines mention pharmacological treatment, case management and complex breathlessness education programmes as possible nursing intervention (NI). In Germany where this study takes place, these are not regular interventions, and there is no requirement to consider such actions. One reason is that most nurses are not familiar with recent developments in evidence-based interventions.

Hence, the postulation to use NPI for breathlessness as found in reviews and studies, ${ }^{9} 1819$ does not automatically lead to an increased use of these interventions by nurses in the management of breathlessness. In addition, nurses may use pharmacological interventions which do not fall within their responsibility. ${ }^{20}$ Compared to other countries, German nurses' scope of responsibility is strictly limited. Most treatment decisions are not allowed to be made by nurses and are not governed by the legal framework. This framework ascribes nurses the responsibility to execute delegated and prescribed treatment correctly. They are not allowed to prescribe any treatment and are not part of treatment decisions. Their main activities on a non-specialised ward are bedside care and administration. A third aspect is that nurses use experience-based interventions like positioning or energy conserving. These interventions are not evidence based and belong to the intuitive knowledge of nurses ${ }^{21-24}$ The question arises as to what nursing interventions in breathlessness are, how nurses decide in these special situations and which factors influence them.

As quality and intensity of breathlessness vary, ${ }^{3} 2526$ nurses' reactions and DM should vary as well. A breathlessness attack always needs prompt reaction, and patients are often too anxious and breathless to interact. This means that the choice of intervention needs to be quick. In other situations, for example, body care or mobilisation, ${ }^{12}$ the emphasis is more on preventive aspects, and the DM process can be more explicit and negotiated within the patient-nurse interaction.

\section{Ethically relevant clinical DM}

DM in clinical practice involves two possible perspectives. First, professionals-nurses, practitioners or other therapists-need to have professional knowledge including physiology, diagnostic and therapies, that is, evidence-based knowledge to judge the individual case. $^{27-29}$ Second, they need to interact with patients and eventually with their family members or (medical, legal) attendants. ${ }^{30} 31$ This perspective is relevant because of legal aspects including informed consent. ${ }^{32}$ Interaction with the patient or family member is central in the concept of DM as a social process, as well as a key point of the professional relationship. It involves the vulnerability and dependency of patients. Therefore, it adds an ethical perspective to the legal responsibility nurses have. ${ }^{31} 32$

\section{Need of DM research in nursing practice}

The DM of professional nurses, especially their treatment choices, is rarely studied. A review of the ethical reasoning and behaviour of nurses identified numerous factors influencing ethical DM such as institutional context, education and professional experience, medical directives or personal values. ${ }^{29}$ However, the international literature reveals wide variations in the nurses' roles, duties and potential DM situations. Some situations primarily involve medical decisions, for example, on withdrawing treatment. Others involve ethical decisions, where nurses have doubts about assistance in euthanasia. Again, in Germany these situations are all excluded by legal regulations. ${ }^{33}$

On the other side nurses' DM is often studied in the context of their role as mediator, translator or advocate of patients and their relatives when treatment decisions are made. ${ }^{34} 35$ This is in line with the mentioned legal responsibility and institutionalised professional duties which vary in different contexts or countries and are often connected to nurses' training or degree as well as their professional level. ${ }^{36} 37$ Both are central aspects of the research question which does not focus on nurses in a subordinated role but as persons in charge. In either case, limited responsibility and duties need to be included in studies addressing nurses' DM.

This article is based on the idea that DM is an interaction between two or more (not necessarily conscious) actors influenced by several factors. This means to distinguish between (1) the observable behaviour resulting from decisions made before and (2) the self-statement of decision-makers with or without any incentive to act. Both approaches are part of DM and its interactive and processual logic ${ }^{3839}$ but do not fully appreciate the complexity of DM. For this reason, they are both part of the study.

The aim of the study is to explore factors influencing the DM processes of nurses with a special focus on NPI for the treatment of breathlessness. It investigates DM in situations where nursing professionals have leeway for decisions.

\section{METHODS AND ANALYSIS}

\section{Study design}

This is a qualitative study combining two different data collection methods, participant observation and expert interviews and data analysis. It merges into an reflexive grounded theory (RGT) approach ${ }^{40}$ which integrates Goffman's framework analysis (FA). ${ }^{41}$ It integrates the 
participants' observable behaviours and their accounts in analysing $\mathrm{DM}$ as an interactive and contextual process. Its underlying theories signify that it is possible to describe the subjective perspective of actors in social situations, ${ }^{42} 43$ as well as the structures of these situations. ${ }^{44}$ These underlying theoretical assumptions are:

- Symbolical Interactionism and American Pragmatism as basic scientific-theoretical foundations of the GT approach. ${ }^{45}$ Its research logic is also part of the enhanced approach of the RGT.

- An ethnographic perspective allows the participation in the living environment of participants and relevant social situations. ${ }^{40}$ For this reason, participant observation $^{46}$ is an elementary aspect of data collection.

- Systematic self-reflection of the researcher and reflection of the research process are conducted by a methodological alienation. ${ }^{40}$ Memos, retrospective confrontation in peer group discussions and a research diary, as well a conceptual framework to be built as a step of the FA are tools to assure this alienation.

In this way, the researcher gains a deep understanding and explanation of the social situation, that is, the phenomenon in question. At the same time the identification of factors influencing social situations (here: the DM) needs to consider the context and structures behind the (re-)actions of participants: the organisation of the social situation itself. ${ }^{41}$ This assumption is essential in other studies which also use parts of the theoretical framework Goffman developed. ${ }^{47-49}$ Goffman's FA adds to the paradigm of symbolical interactionism, the issue of potential problematic structures of the general understanding in communication. ${ }^{41}$ 'What is going on here? ${ }^{41}$ is the main question, and the answer results from the behaviour and reactions of participants.

\section{Setting and study population}

Special medical fields are chosen for data collection such as palliative or hospice care and respiratory medicine or cardiology. Patients in these settings are more likely to have breathlessness due to their underlying diseases. At the same time the settings vary regarding organisational structure or focus and different stages in disease course. These differences provide initial information for probable theoretical sampling. Potential participants are professional nurses working with patients suffering from severe breathlessness. Apart from the nurses' professional context, inclusion criteria are working in the setting for more than 2 years and giving informed and ongoing consent. Observed patients need to have severe breathlessness, either as diagnosis on admission, general symptom (distractive and leading symptom) or acute attack. They also need to give informed and ongoing consent.

The use of participant observation in daily practice and during situations when patients have severe breathlessness affects other groups in addition to the involved nurses. These are:
- Patients with breathlessness themselves

- Other staff members

- Visitors

- Family members

They are informed by posters, information sheets and the researcher's general introduction.

\section{Theoretical sampling}

Following the RGT approach, a purposive, theoretical sampling is used to focus on special phenomena or categories and to contrast them. ${ }^{40} 4550$ The initially evolving categories are first theoretical steps and guide further sampling. Therefore, the participant observations start broadly, focus on important points emerging through the process of analysis ${ }^{51}$ and are contrasted by qualitative interviews with the observed nurses containing their accounts and reflections. ${ }^{52}$ First expected theoretical aspects guiding the sampling are the special field/discipline, institutional policies and culture, implemented structures of care, available resources as well as individual work experience. Therefore, the initial sampling consists of an internal ward including palliative care in a regional hospital, a respiratory ward in a university hospital and an inpatient hospice supported by a hospice society. These institutions are located in an industrial area in North Rhine-Westphalia, Germany, but data collection is not limited to this province.

Approximately five to seven institutions will be included in data collection. In each institution, two to three nurses will be observed several times and interviewed afterwards. The sample will include male and female nurses with different degrees and work background.

\section{Field access}

Getting field access is a challenge in studies using participant observation. Many colleagues feel uncertain, if care situations could be identified which they experience as unsatisfactory. Recruitment of affected patients is also problematic because they are highly vulnerable. In addition, many institutional aspects, stakeholders and their interests need to be considered. For instance, management and workers' councils in each institution, the ward's team and finally the participating nurses all need to agree with participating in the research. In this study, the researcher will contact the nursing management of relevant institutions by mail or telephone. As gatekeepers they can help to get permission to the institution and its relevant stakeholders. The nursing teams will be contacted simultaneously or shortly afterwards, depending on the gatekeepers' recommendations. After the researcher's introduction and a presentation of the study, the team and each individual nurse have to decide if they want to take part in the study.

\section{Research process}

Given the two methodological backgrounds of RGT and FA, data collection and analysis integrates them through triangulation. ${ }^{53}$ Participant observations and qualitative 
expert interviews will be analysed separately and differently. At the same time, the whole process is iterative and interactive using constant comparison, the coding paradigm and the synthesis through reflexivity as main aspects off the RGT approach. ${ }^{40}$ Figure 1 shows the whole research process. This process will be completed by the time of saturation, that is, no further concepts will amplify the developed theory.

\section{Data collection methods}

Participant observations $\operatorname{are}^{46}$ understood as a process $^{51}{ }^{52}$ (see figure 1) where the researcher needs to behave adequately in the field,$^{51}$ towards participants and in situations as they arise. Therefore, language and clothing can be as important as trustworthiness, an open, non-judgmental contact or quiet listening.

In ethnography, participant observation is also described as the researcher's attitude during field research shifting repeatedly between the role of participant and observer. ${ }^{54}$ This poses a great challenge for researchers as their continuous self-reflection is required to handle potential (inner-) conflicts between observing and participating. In the context of the study and data analysis, this also means reflecting on one's own socialisation and assumptions about what is going on in a special situation. The researcher $(\mathrm{CD})$ is trained as a nurse. This facilitates orientation in as well as access to the field. However, it also reinforces potential role conflicts.

In this study, participant observations cover one shift including overtime and are comparable to an internship or job shadowing. Usually, one nurse is accompanied for the entire duration, with the exception of situations in which the affected persons have not consented. Field notes are written down during the observation. They are oriented on open questions guiding the researcher's perception (Who? What? How? Where? With whom? Why? When?). During the research process, participant observation should specify and may focus on, single aspects such as special breathlessness situations or the team structure.

The qualitative expert interviews have a narrative character. $^{5556}$ They take place in a familiar atmosphere and at a place of the participants' choice. After an explanation of the narrative character of the interview, an initial question is asked: 'Please try to remember two patients with breathlessness you cared for and situations in which they had severe breathlessness. What did you do in these situations and why did you do it?'

In the process of a narrative interview ${ }^{56}$ the phase of the participant's narration is followed by further enquiry. A second part of the interview uses findings from participant observations to reflect them ${ }^{52}$ and to generate descriptions of participants' implicit interpretation patterns. These findings will change within further theory development, that is, the second interview part will change during the research process. A first example is shown in the online supplementary file 1 .

\section{Data analysis methods}

The analysis is computer guided using F4 to transcribe the audiotaped interviews verbatim, and MAXQDA to analyse the observations protocols as well as the interview transcripts. 
As defined by the RGT approach, data analysis and data collection are simultaneous and circular. ${ }^{40} 4550$ Theoretical sampling will be conducted and the coding process will involve the coding paradigm as well as the method of constant comparison.

The notes from participant observations will be written down as observation protocols. ${ }^{51}{ }^{54}$ These protocols can be analysed using the FA design (about the explanations of Flick ${ }^{52}$ ), illustrated in three steps conducted in circular fashion. All steps of this approach and their measures are also illustrated in the online supplementary files (supplement 2).

1. Sequence analysis: The protocols will be sectioned and the emerging sequences will be named/labelled. Apart from the general time elapse of the shift and its organisational operations, some of the sequences will be strictly sorted in chronological order. They can also be mixed with descriptions about the way things are carried out or the aims behind a (re-) action, the way of communication and specific situations giving the observer food for thought. However, the time elapsed and the chronology of special situations will be reconstructed.

2. Development of construct frameworks and a leading perspective: assisted by questions developed from the Theory of FA, this step aims to identify the organisational structures or principles of 'what is going on' in a social situation. Apart from the structured analysis of the situations, different theoretical perspectives are applied to the recorded situations. One leading perspective will be formulated at the end of the process.

3. Generation of typologies: The identification of commonalities and differences out of the described organisational principles (step 1 and 2) allows us to typify different situations, that is, the actors' behaviour and the underlying structures. Thereby it is possible to compare and contrast influencing factors which occur in focused breathlessness situations and general participant observations as well as in different institutions.

The transcribed expert interviews will be coded in an open, axial and selective format following the GT approach. ${ }^{50}$ Open coding will be conducted to identify occurring phenomena that can be compared, questioned and sorted via codes, whereas axial coding aims to systematically analyse key categories. Relations between different categories are described on the basis of the data material. The coding paradigm ${ }^{45}$ with its subcategories and generative questions are used in this coding phase. Thus the researcher identifies correlational models of the evolving theory and rarefies them. Finally, in the phase of selective coding, the researcher develops the core category out of the data material and the previous correlational models.

\section{Integration of RGT and Goffman's FA}

As stated before, the analysis of participant observation follows the FA. The results of this process will be integrated into the coding paradigm. Then they will be analysed together with the data from the expert interviews (figure 2). The coding paradigm is also shown in figure 2. It answers the main question of 'What is going on here?' This central phenomenon and its described strategies are then related to its contextual factors which appear to constitute the influencing factors of the DM process described.

This integration is possible because of the related basic distinctions of the underlying microsociological interaction theories and similar methodological approaches explained before. At the same time, the FA and its use as data analysis for the participant observations allows to examine the social interaction with its symbols and assumed roles and the organisational structures of the social interaction itself. ${ }^{57} 58$ It provides the theoretical framework as operationalised in this study to analyse the data. ${ }^{44}$

\section{Ethics and dissemination}

The participants are nurses, that is, experts, who share some of their professional experiences and decisions as well as their daily work. In the interviews, they may be confronted with unpleasant memories or reflections but are not likely to be vulnerable.$^{59}$ The atmosphere of the interviews should be informal and personal, and the recorded part will be embedded in an open and cooperative conversation.

Several aspects need to be considered during participant observation. The institutional setting with its own structures is one, but different persons involved (see 'study population') demand the researcher's sensitivity to possible irritations or uncertainties, for example, when nurses feel controlled, or when other staff members not participating in the study do not wish to be mentioned. Conflicting interests may arise; for example, participants may ask the observer to take over part of the nursing care herself to compensate staff shortage. In addition, the observed situations are often intimate interactions within the caring relationship or highly vulnerable situations of patients experiencing breathlessness, that is, an existential and threatening symptom.

Therefore, the researcher needs to assure participants that informed and ongoing consent is warranted, and no information about participating nurses will be passed on to senior staff or the institution. ${ }^{59}$ To achieve this purpose

1. A written Study Information leaflet is handed out and repeated orally before the data collection starts. Participating nurses and involved patients give their written informed consent and repeat their ongoing consent orally. ${ }^{59}$

2. The management as well as workers' representatives or council will control this procedure and need to give their consent, too.

3. Data will be pseudoanonymous, but no data will be recognisable by others than the researcher. 


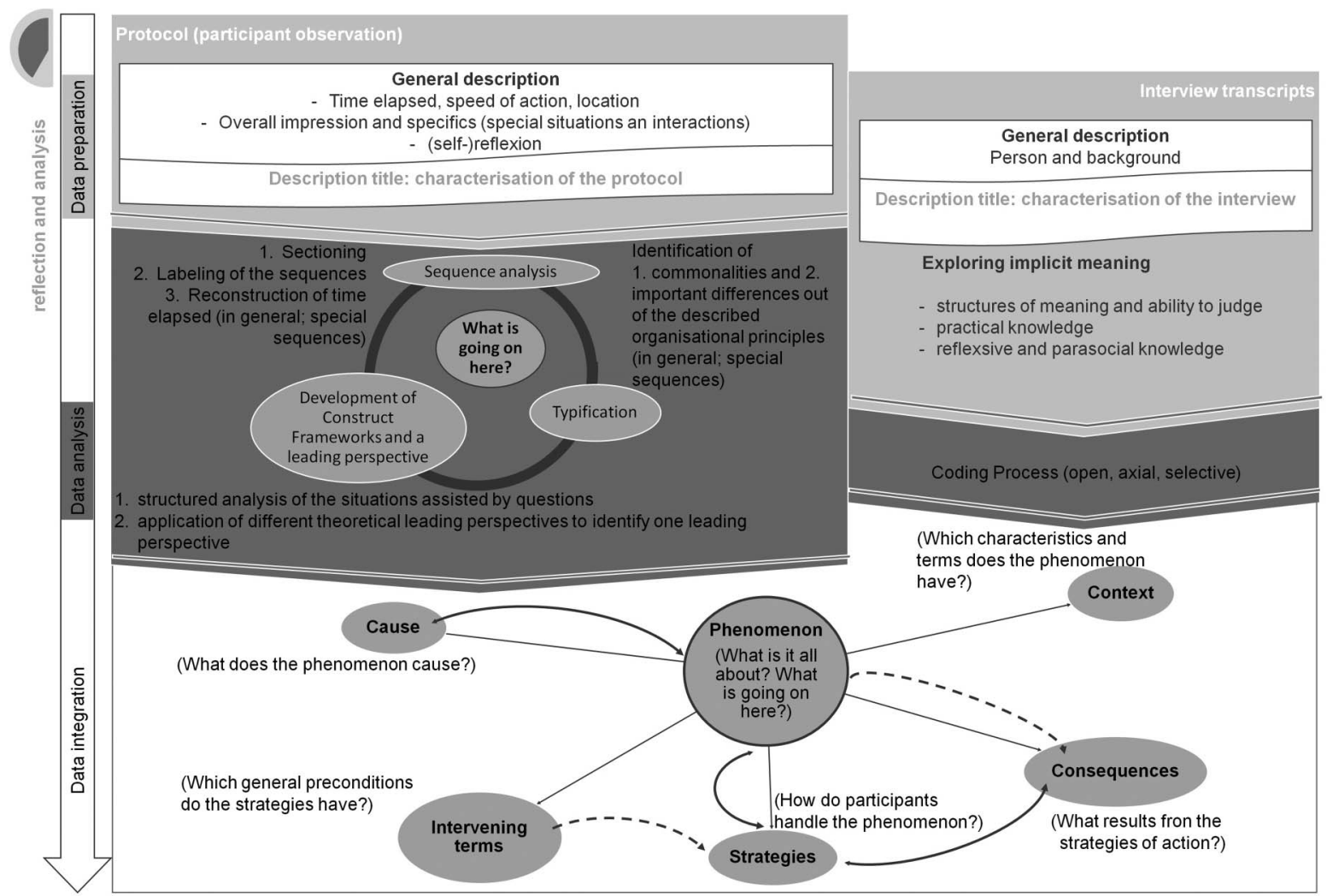

Figure 2 Integration of reflexive grounded theory and Goffman's framework analysis.

Results of the study will be presented at several congresses and in all participating institutions. They also will be published in high-quality peer-reviewed international journals and in German journals addressing registered nurses. Finally, the study will be distributed as $\mathrm{PhD}$ thesis.

\section{DISCUSSION}

The study aims to explore nurses' DM in a special clinical situation under consideration of factors influencing this interactive process. It was inspired by two major aspects. One is the challenging symptom of breathlessness often urging nurses to react in an acute clinical situation but without clear instructions on which interventions to use. In addition, work circumstances vary and foster or inhibit possible treatment options. Second, nurses' DM in breathlessness situations is a professional interaction with a vulnerable person. There is little knowledge about ethically relevant clinical DM and its influencing factors in daily care, especially with the focus on decisions where the nurses need to act and cannot delegate their responsibility.

Findings help to explore the specific perspective on nurses' treatment choices in breathlessness and their implicit knowledge about interventions to palliate severe breathlessness. Thereby, the study will provide insights into nurses' decision-making processes and the main factors including relation to different settings, knowledge, persons or circumstances.
The results could help to initiate a practice development process with regard to institutional aspects and guide the clinical care for breathless patients. They may also give first indications for further research on hitherto disregarded nursing interventions in severe breathlessness. The clarification of treatment options within the patient-nurse interaction could influence the focus on NPI and their meaning for different qualities or durations of breathlessness. This has implications in daily practice for German nurses but for other nursing staff. ${ }^{16}$ Results may also influence the discussion about nurses' scope of responsibility in breathlessness care.

From a methodological perspective, we acknowledge that sociologists have been discussing the implications of Goffman's theories for psychiatry, nursing homes and also hospitals. ${ }^{60} 61$ This outside perspective is hardly adopted in health research, albeit a few qualitative studies of practice reflection discuss it. ${ }^{62}$ The integration of an RGT approach and the FA as an approach for data analysis may supplement sociologists' results and theories with findings from an inside perspective of health research. At the same time, FA applied in health research could add aspects to (Nursing) DM or Interaction Theories.

Overall, the use of the introduced triangulated design is complex and has to show its practicability and utility for health research. Nevertheless, this systematic but open application of the FA gives this important theory some elements of structure which are important for use as research design. 
Limitations may be attributed to challenges in field access as mentioned. As this is a qualitative study, its results are valid for the population and circumstances under study but cannot be generalised easily. Finally, it remains to be seen whether the chosen theory-based approach will do justice to the different levels of ethically relevant clinical DM, the patient-nurse interaction, the clarification of treatment options and possible frictions between these aspects.

Acknowledgements The authors thank Dipl.-Dolm. Christina Wagner, Witten/ Herdecke University and Natalie Ontko-Price for language support with the manuscript. Martin Czerwanski also read the manuscript and gave an important input in form and content.

Contributors All authors contributed to the development and design of the study protocol. CD wrote the initial draft of the protocol. She is responsible for the conception of this project as PhD thesis and conducts the observations and interviews. CD drafted the manuscript with critical input from all other authors who have read and approved the final manuscript.

\section{Competing interests None declared.}

Ethics approval The protocol of the present study was approved by the Witten/Herdecke University Ethics Committee in Witten, Germany.

Provenance and peer review Not commissioned; externally peer reviewed.

Open Access This is an Open Access article distributed in accordance with the Creative Commons Attribution Non Commercial (CC BY-NC 4.0) license, which permits others to distribute, remix, adapt, build upon this work noncommercially, and license their derivative works on different terms, provided the original work is properly cited and the use is non-commercial. See: http:// creativecommons.org/licenses/by-nc/4.0/

\section{REFERENCES}

1. American Thoracic Society. Dyspnea. Mechanisms, assessment, and management: a consensus statement. Am J Respir Crit Care Med 1999;159:321-40.

2. Parshall MB, Schwartzstein RM, Adams L, et al. An official American Thoracic Society statement: update on the mechanisms, assessment, and management of dyspnea. Am J Respir Crit Care Med 2012;185:435-52.

3. Simon ST, Higginson IJ, Benalia $\mathrm{H}$, et al. Episodes of breathlessness: types and patterns-a qualitative study exploring experiences of patients with advanced diseases. Palliat Med 2013;27:524-32.

4. Strang S, Ekberg-Jansson A, Henoch I. Experience of anxiety among patients with severe COPD: a qualitative, in-depth interview study. Palliat Support Care 2014;12:465-72.

5. Cachia E, Ahmedzai SH. Breathlessness in cancer patients. Eur J Cancer 2008;44:1116-23.

6. Kvangarsnes M, Torheim H, Hole T, et al. Narratives of breathlessness in chronic obstructive pulmonary disease. J Clin Nurs 2013;22:3062-70.

7. McCarthy B, Casey D, Devane D, et al. Pulmonary rehabilitation for chronic obstructive pulmonary disease. Cochrane DatabaseSyst Rev 2015;(2):CD003793.

8. Kwekkeboom KL, Bratzke LC. A systematic review of relaxation, meditation, and guided imagery strategies for symptom management in heart failure. J Cardiovasc Nurs 2016;31:457-68.

9. Bausewein C, Booth S, Gysels M, IJ, et al Non-pharmacological interventions for breathlessness in advanced stages of malignant and non-malignant diseases. Cochrane Database Syst Rev 2008;(2): CD005623.

10. Akinci AC, Olgun N. The effectiveness of nurse-led, home-based pulmonary rehabilitation in patients with COPD in Turkey. Rehabil Nurs 2011;36:159-65.

11. Bailey C. Nursing as therapy in the management of breathlessness in lung cancer. Eur J Cancer Care (Engl) 1995;4:184-90.

12. Jensen AL, Vedelø TW, Lomborg K. A patient-centred approach to assisted personal body care for patients hospitalised with chronic obstructive pulmonary disease. J Clin Nurs 2013;22:1005-15.

13. Tod AM, Redman J, McDonnell A, et al. Lung cancer treatment rates and the role of the lung cancer nurse specialist: a qualitative study. BMJ Open 2015;5:e008587.
14. Registered Nurses' Association of Ontario. Nursing Care of Dyspnea: The 6th Vital Sign in Individuals with Chronic Obstructive Pulmonary Disease (COPD). Toronto, Canada: Registered Nurses' Association of Ontario, 2005.

15. Marciniuk DD, Goodridge D, Hernandez P, et al. Managing dyspnea in patients with advanced chronic obstructive pulmonary disease: a Canadian Thoracic Society clinical practice guideline. Can Respir $J$ 2011;18:69-78.

16. Johnson M, Moore S. Research into practice: the reality of implementing a non-pharmacological breathlessness intervention into clinical practice. Eur J Oncol Nurs 2003;7:33-8.

17. Wagland R, Ellis J, Bailey $\mathrm{CD}$, et al. Considerations in developing and delivering a non-pharmacological intervention for symptom management in lung cancer: the views of health care professionals. Support Care Cancer 2012;20:2565-74.

18. Barnett $M$. Nursing management of chronic obstructive pulmonary disease. Br J Nurs 2008;17:1314-18.

19. Buckholz GT, von Gunten CF. Nonpharmacological management of dyspnea. Curr Opin Support Palliat Care 2009;3:98-102.

20. Autorenkollektiv. Bürgerliches Gesetzbuch. 66th edn. München: Deutscher Taschenbuch Verlag, 2010.

21. Layer M. Wickel aktivieren Selbstpflegekräfte. Pflegen:palliativ 2010;7:20-3.

22. Riegler U. Die Bedeutung der Aromapflege in der Palliative Care mit Schwerpunktsetzung schmerz- und angstlindernde Maßnahmen (Thesis). University of Vienna, 2010.

23. Watson $\mathrm{S}$, Watson $\mathrm{S}$. The effects of massage: a holistic approach to care. Nurs Stand 1997;11:45-7.

24. Ulmer EM, Höhmann U, Linhart M, et al. Der Einsatz von interaktionsintensiven pflegetherapeutischen Maßnahmen und von "Hausmitteln" in der Pflege. Pflege 2001;14:191-205.

25. Gysels M, Higginson IJ. The experience of breathlessness: the social course of chronic obstructive pulmonary disease. J Pain Symptom Manage 2010;39:555-63.

26. Gysels MH, Higginson IJ. The lived experience of breathlessness and its implications for care: a qualitative comparison in cancer, COPD, heart failure and MND. BMC Palliat Care 2011;10:15.

27. Lake SE, Moss C, Duke J. Nursing prioritization of the patient need for care: a tacit knowledge embedded in the clinical decision-making literature. Int J Nurs Pract 2009;15:376-88.

28. Thompson C, McCaughan D, Cullum N, et al. Research information in nurses' clinical decision-making: what is useful? J Adv Nurs 2001;36:376-88.

29. Goethals S, Gastmans C, de Casterlé BD. Nurses' ethical reasoning and behaviour: a literature review. Int J Nurs Stud 2010;47:635-50.

30. Yoos HL, Kitzman H, McMullen A, et al. The language of breathlessness: do families and health care providers speak the same language when describing asthma symptoms? J Pediatr Health Care 2005;19:197-205.

31. Schnell MW. Patientenverfügung. Begleitung am Lebensende im Zeichen des verfügten Patientenwillens-Kurzlehrbuch für die Palliative Care. Bern: Hans Huber Verlag, 2009.

32. Schnell M. Ethik als Schutzbereich. Kurzlehrbuch für Pflege, Mediztin und Philosophie. Bern: Hans Huber Verlag, 2008.

33. Weigend T. Strafgesetzbuch StGB. 47th edn. München: Deutscher Taschenbuch Verlag, 2009.

34. McMillen RE. End of life decisions: nurses perceptions, feelings and experiences. Intensive Crit Care Nurs 2008;24:251-9.

35. Zomorodi M, Lynn MR. Instrument development measuring critical care nurses' attitudes and behaviors with end-of-life care. Nurs Res 2010;59:234-40.

36. Weidner F. Professionelle Pflegepraxis und Gesundheitsförderung. Eine empirische Untersuchung über Voraussetzungen und Perspektiven des beruflichen Handelns in der Krankenpflege. 3rd edn. Frankfurt am Main: Mabuse-Verlag, 2004.

37. Benner P. Stufen zur Pflegekompetenz. From novice to expert. Bern: Hans Huber Verlag, 1994.

38. Traynor M, Boland M, Buus N. Autonomy, evidence and intuition: nurses and decision-making. J Adv Nurs 2010;66: $1584-91$.

39. Dunger C, Schnell MW. Pflegerische Entscheidungen am Lebensende. Pflege Z 2012;65:170-5.

40. Breuer F. Reflexive grounded-theory. eine Einführung für die Forschungspraxis. Wiesbaden: VS-Verlag, 2009.

41. Goffman E. Frame analysis: an essay on the organization of experience. New York: Harper \& Row, 1974.

42. Bailey PH, Tilley S. Storytelling and the interpretation of meaning in qualitative research. J Adv Nurs 2002;38:574-83.

43. Holloway I, Wheeler S. Qualitative research in nursing and healthcare. 3rd edn. Oxford: Wiley-Blackwell, 2010. 
44. Willems H. Goffmans qualitative Sozialforschung. Ein Vergleich mit Konversationsanalyse und Strukturaler Hermeneutik. Zeitschrift für Soziologie 1996;25:538-455.

45. Strübing J. Grounded theory-Zur sozialtheoretischen und epistemiologischen Fundierung des Verfahrens der empirisch begründeten Theoriebildung. 2nd edn. Wiesbaden: VS-Verlag, 2008.

46. Atkinson P, Hammersley M, Denzin NK, et al. Ethnography and participant observation. In: Denzin NK, Lincoln YS, eds. Handbook of qualitative research. Thousand Oaks, CA, USA: Sage Publications, 1994:248-61.

47. Lillehagen I, Vøllestad N, Heggen K, et al. Protocol for a qualitative study of knowledge translation in a participatory research project. BMJ Open 2013;3:e003328.

48. Antoniou T, Loutfy MR, Glazier RH, et al. 'Waiting at the dinner table for scraps': a qualitative study of the help-seeking experiences of heterosexual men living with HIV infection. BMJ Open 2012;2: e000697.

49. Abildsnes E, Flottorp S, Stensland P. Case stories in general practice: a focus group study. BMJ Open 2012;2:e001208.

50. Strauss AL, Corbin JM. Basics of qualitative research: grounded theory procedures and techniques. London, New Delhi, New York: Sage Publications, 1990.

51. Kawulich BB. Participant observation as a data collection method. Forum: Qual Soc Res 2005;6:43.

52. Flick U, von Kardorff E, Steinke I. Qualitative Forschung-Ein Handbuch. Reinbek: Rowohlt Taschenbuch Verlag, 2000

53. Mayring P. Combination and integration of qualitative and quantitative analysis. Forum: Qual Soc Res 2001;2:6.
54. Schnell MW, Schneider W, Kolbe H. Sterbewelten. Eine Ethnographie. Wiesbaden: VS-Verlag, 2013.

55. Mruck K, Mey G. Qualitative Sozialforschung in Deutschland. Forum Qual Soc Res 2000;1:4.

56. Atkinson P, Bauer MW, Gaskell G. Qualitative researching with text, image and sound: a practical handbook for social research. London, Thousand Oaks, New Delhi: SAGE, 2000.

57. Hettlage R. Rahmenanalyse-oder die innere Organisation unseres Wissens um die Ordnung der sozialen Wirklichkeit. In: Hettlage R, Lenz K, eds. Erving Goffman: ein soziologischer Klassiker der zweiten Generation. Stuttgart: Haupt, 1991:95-154.

58. Eberle TS. Rahmenanalyse und Lebensweltanalyse. In: Hettlage R, Lenz K, eds. Erving Goffman: ein soziologischer Klassiker der zweiten Generation. Stuttgart: Haupt, 1991:157-210.

59. Schnell MW, Heinritz C. Forschungsethik. Ein Grundlagen- und Arbeitsbuch für die Gesundheits- und Pflegewissenschaft. Bern: Hans Huber Verlag, 2006.

60. Vogd W. Die Bedeutung von "Rahmen" (frames) für die Arzt-Patient-Interaktion: eine Studie zur ärztlichen Herstellung von dem, "was der Fall ist" im gewöhnlichen Krankenhausalltag Zeitschrift für qualitative Bildungs-, Beratungs- und Sozialforschung 2002;3:321-46.

61. Hanisch-Berndt J. Gemeinschaft und Vereinsamung in Einrichtungen der stationären Altenhilfe (Thesis). Free University of Berlin, 2005.

62. Heinzelmann M. Das Altenheim-immer noch eine "Totale Institution"? Eine Untersuchung des Binnenlebens zweier Altenheime. Göttingen: Cuvillier Verlag, 2004. 